\title{
Selected properties of biodegradable material produced from thermoplastic starch with by-products of food industry addition
}

\author{
Ewa Zdybel*, Ewa Tomaszewska-Ciosk, Mateusz Gertchen, Wioletta Drożdż \\ Wroctaw University of Environmental and Life Sciences, The Faculty of Food Science, ul. Chetmońskiego 37, \\ 51-630 Wroctaw, Poland \\ Corresponding author: e-mail: ewa.zdybel@up.wroc.pl
}

\begin{abstract}
In this work extrusion process were used to create thermoplastic starch and to mix obtained starch with linen, quince and apple pomace at the same time. Obtained starch beads were formed in shapes. In experimental material was determined thermal conductivity, water absorption and the solubility in water. It is possible to get the biodegradable material produced from thermoplastic starch with an addition of fruit pomace. Adding pomace and glycerine to the biodegradable material made from starch change of susceptibility on water action. In the case of materials containing pomace, glycerine addition decreases the susceptibility on water action compared to the material manufactured with pomace addition but without glycerine. In the material containing pomace, glycerine addition caused the increase of the thermal insulation time compared to the material with pomace but no glycerine in it.
\end{abstract}

Keywords: thermoplastic starch, biodegradable material, potato starch, fruit pomace.

\section{INTRODUCTION}

Nowadays, very fast development of civilization and the necessity to balance high industrialization with care of the environment, is forcing to search innovative solutions. New technologies have to fulfill high requirements also in respect of ecology. One of the problems is to find production method of biodegradable materials.

The dynamic progress of economy, industry and trade has increased production of packages. The most widespread materials for packages production are synthetic, polymer plastic produced from fraction of petroleum. These materials have very good functional properties. They are durable and resistant to environment conditions. Owing to their thermoplastic properties there are no problems to shape them. Moreover low real mass of synthetic materials supports their logistics and transport. Packages from synthetic plastics meet their demands. They are easy traded, attractive in regard to marketing issues, cheap and they protect products from external factors. However mentioned properties become a problem in ecology issues. Decomposition of synthetic polymers in the natural environment is virtually impossible which in connection with rapid increase of packages production brought an accumulation of waste permanent in environment. Both management and utilization of waste produced from synthetic polymers are difficult because these are expensive and ineffective processes ${ }^{1}$.

Technical and economic problems connected with packages recycling are forcing to search new production technologies for plastic susceptible for biodegradation and organic recycling. Research conducted by scientists are aimed to find production method for completely or partly biodegradable package material. Moreover, that material should be characterized by functional properties similar to synthetic polymers.

One of the natural biodegradable material which can be useful for biodegradable plastics production is starch. Starch is a renewable material, produced by plants in the photosynthesis process. It is cheap and readily available. As reported by literature there are some technologies for using starch for biodegradable plastics production. One of the methods to obtain partly biodegradable synthetic plastics is to incorporate starch chains in plastics chemical structure ${ }^{2}$. In that compositions starch acts as the factor increasing polymer susceptibility for biodegradation ${ }^{3}$. Apart from partly biodegradable material production scientists are looking for methods for completely biodegradable material production. In the literature some methods are described to obtain starch foils ${ }^{4,5}$. Those foils are produced from starch mucilage mixed with plasticizer and dried. In order to improve the structure and properties of obtained starch film, authors used various additives such as kaolin, cellulose chitosan or guma guar. Foils achieved in that way were characterized by lower susceptibility for water action, better mechanical properties and bigger antibacterial activity compared to foil obtained from starch only ${ }^{5,6,7,8}$.

Starch application for biodegradable plastic production requires its plastification. It is connected with the semi-crystalline structure of starch granules destruction and lowering the temperature of material liquefying. The most popular methods for starch plastification is adding of a plasticizer such as glycerine, glycol, sorbitol or urea, 10 . The plastic production process from thermoplastic starch could be made using traditional methods characteristic for plastic production such as: pressing, injection or extrusion $^{11}$. The extrusion process is associated with starch gelatinization with crystal structure destruction. Depending on the extrusion parameters and plasticizer addition it is possible to get thermoplastic starch usable for package material production.

In this work extrusion process were used to create thermoplastic starch and to mix obtained starch with fruit pomace at the same time. Fruit pomace is formed as by-product during the production of juices ${ }^{12}$. Some of it is used as feed additive, in the distillery and winery, production of purées and fruit teas, and also as a raw material to pectin, fiber, dyes and energy production ${ }^{13}$. The possibility of using fruit pomace as biodegradable material additive is a new way to use it as a by-product.

Development of biodegradable packaging materials industry based on starch is an interesting and ecologically important direction of research. It needs to strive to make a material with good functional properties. Elabo- 
ration of water resistant biodegradable starch material is particularly difficult. There is a possibility to obtain biodegradable packaging material distinguished by low thermal conductivity so that this material can be used as package for temperature changes sensitive products.

\section{MATERIAL AND METHODS}

The materials used in the experiment were: Potato starch produced by PEPEES S.A in Łomża in 2013, glycerine from Alrdrich company, linen pomace produced by Oleofarm company (2012); and apple and quince pomace obtained from Department of Fruit, Vegetable and Cereals Technology of Wrocław University of Environmental and Life Sciences in 2014. Pomaces were dried convectional at $40^{\circ} \mathrm{C}$ for 48 hours, after that pomaces were ground and immediately used in the experiment. Potato starch and linen pomace were delivered from producers in original packages and stored (temp. $20^{\circ} \mathrm{C}$, humidity $55 \%$ ) until the experiment was started.

Potato starch was mixed manually with glycerine in an amount of 10 and $15 \%$ glycerine in relation to dry weight of the starch and with the addition of apple, quince or linen pomace in concentration of $5 \%$ or $10 \%$ in relation to dry weight of the starch. The water content of the mixture was adjusted to $25 \%$, then the mixture was conditioned in tightly closed containers at $20^{\circ} \mathrm{C}$ for 24 hours.

The obtained samples were extruded in the singlescrew extruder, Brabender type 20DN at temperatures $90^{\circ} \mathrm{C}-100^{\circ} \mathrm{C}-120^{\circ} \mathrm{C}$ (accordingly: I, II and III sections of extruder); The rotation speed of the screw was set to $120 \mathrm{rev} / \mathrm{min}$, the speed of material feeding was set to $60 \mathrm{rev} / \mathrm{min}$, the compression rate of the screw $2: 1$. The granulate attachment was used with a knife rotating at speed of $90 \mathrm{rev} / \mathrm{min}$.

Obtained starch beads were formed in shapes ${ }^{\mathbf{1 4}}$. Starch beads were moistened by the addition of water in mass of $5 \%$ of dry pellet mass. Moistened pellet was placed in the form, stirred for 10 seconds and then compacted with $100 \mathrm{~N}$ pressure. Filled forms were dried at $30^{\circ} \mathrm{C}$ for 24 hours . After that dry shapes were removed from the form and analyzed. The structure of obtained material was compact in the cylinder shape with $2 \mathrm{~cm}$ diameter and $2 \mathrm{~cm}$ height.

The thermal conductivity of material was determined to measure time of temperature equalization inside of the shape placed in the copper cylinder in water bath at $70^{\circ} \mathrm{C}^{\mathbf{1 4}}$. The material with higher thermal conductivity had shorter time of temperature equalization inside the form.

Water absorption was determined at $30^{\circ} \mathrm{C}$ and $80^{\circ} \mathrm{C}^{\mathbf{1 5}}$. Experimental material was placed in water at temperature $30^{\circ} \mathrm{C}$ or $80^{\circ} \mathrm{C}$ and stored in this conditions for 1 hour. Then this material was moved on the blotting paper and after drying of outer surface weighed. Water absorption was calculated from the formula: $\mathrm{W}=100(\mathrm{~K}-\mathrm{L}) / \mathrm{L}(100-\mathrm{R})$,

where $\mathrm{W}$ - absorption (grams of water/ grams of product), $\mathrm{K}$ - mass of the material after soaking ( $\mathrm{g})$, L - dry weight of the material before soaking $(\mathrm{g}), \mathrm{R}-\operatorname{solubility}(\%)$.

The solubility in water at $30^{\circ} \mathrm{C}$ and $80^{\circ} \mathrm{C}$ was determined $^{\mathbf{1 5}}$. The material was placed in the $250 \mathrm{ml}$ beaker containing $30^{\circ} \mathrm{C}$ or $80^{\circ} \mathrm{C}$ water and stored in these conditions for 1 hour. Then the content of the beaker was filtered through dried and tared paper filter. The paper filter with the examined material was dried at $105^{\circ} \mathrm{C}$ to total drying. The solubility in water was calculated from the following formula: $\mathrm{R}=100(\mathrm{~L}-\mathrm{N}) / \mathrm{L}$,

where: $\mathrm{R}$ - solubility (\%), L - dry weight of the material before soaking $(\mathrm{g}), \mathrm{N}$ - mass of the examined material after drying $(\mathrm{g})$.

The obtained results were developed statistically in Statistica 9.0 programme. The three-factorial, (the type of pomace, the amount of pomace addition, the amount of glycerine addition) one- and two-way ANOVA tests were used. The least significant difference between the average values of results was calculated using Duncan test at a significance level of $\alpha \leq 0,05$.

\section{RESULTS AND DISCUSSION}

The potato starch after extrusion is characterized by high water operation. The solubility of extruded starch in $80^{\circ} \mathrm{C}$ water can approach to $80 \%{ }^{\mathbf{1 6 - 1 9}}$. The water absorption and the solubility of material prepared from extruded starch, determined in this work, achieved lower in comparison with literature data. Probably, the process of material formation contributed to seal the structure and therefore water operation was lower compared to unstructured extruded starch. Figure 1 illustrates the dependency of water absorption at $30^{\circ} \mathrm{C}$ versus amount and type of used pomace. Slightly increase of water absorption at $30^{\circ} \mathrm{C}$ in material produced with pomace addition was observed, however no influence of the pomace amount has been established. Analyzing the impact of pomace type it was found that apple pomace addition didn't cause the water absorption compared to water absorption of material produced from starch without pomace addition. In the case of water absorption measured at $80^{\circ} \mathrm{C}$, the

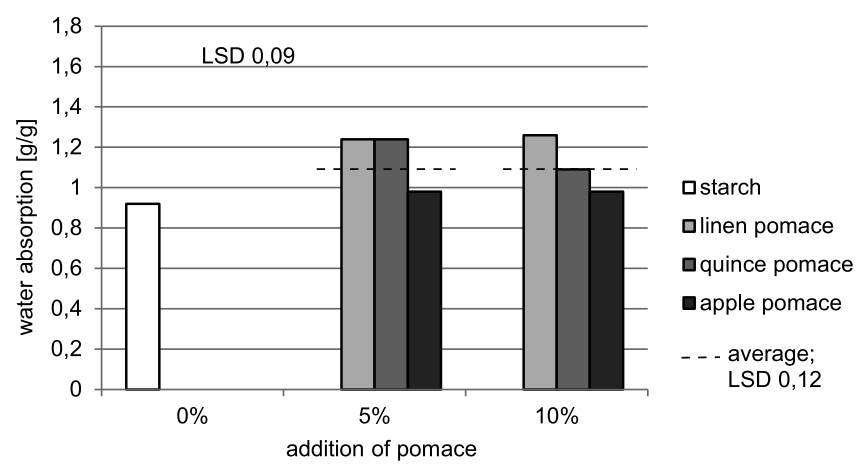

Figure 1. The water absorption at $30^{\circ} \mathrm{C}$, depending on the size and type of pomace

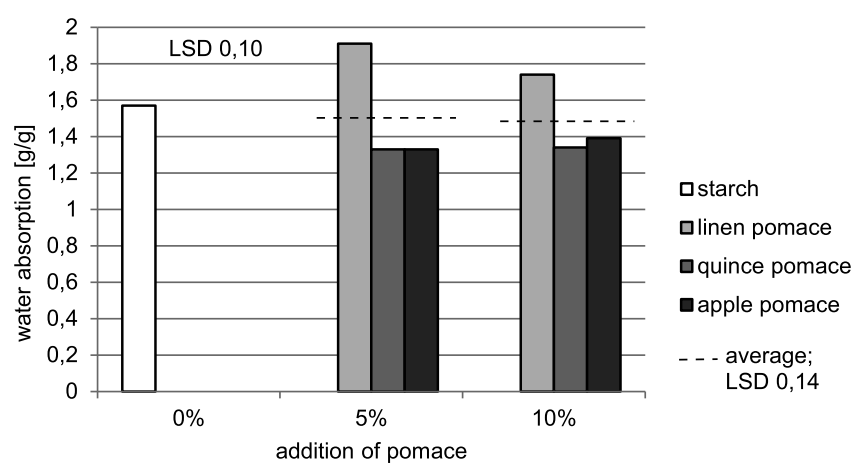

Figure 2. The water absorption at $80^{\circ} \mathrm{C}$, depending on the size and type of pomace 
addition of fruit pomace had no impact on water absorption of the tested material (Fig. 2). However, analyzing influence of individual types of pomace, it was found that water absorption decreased as a result of apple and quince pomace addition. It can be presumed that pomace's fibers in the manufactured material were stuck with exdruded starch and effectively blocking access to the hydrophilic extruded starch. Interesting is that water absorption increased at $80^{\circ} \mathrm{C}$ in the material containing linen pomace. Relatively smallest water absorption in the material with linen pomace addition was expected because this additive contains from a few to a several percents of hydrophobic fat ${ }^{20}$. Presumably, fatty linen pomace prevented from creating the compact structure of material during the forming process which is based on moisturization of extruded starch beads. Because of that surface layer of pellet dissolves and becomes a binder which permanently connects each bead. The fat included in linen pomace made the connection of pellet insufficient, therefore water had better access to the finished material.

Analyzing the influence of addition of the pomace on solubility in $30^{\circ} \mathrm{C}$ or $80^{\circ} \mathrm{C}$ water, there was no impact on average (Figs. 3, 4). In the case of measurement at $80^{\circ} \mathrm{C}$ the average value of solubility increased as a result of $5 \%$ pomace addition compared to the material formed without pomace addition as well as with $10 \%$ addition. Interesting is the fact, that the biggest increase of solubility both at $30^{\circ} \mathrm{C}$ and $80^{\circ} \mathrm{C}$ water was observed after using quince pomace. Probably this pomace, apart from insoluble in water polysaccharides ${ }^{21,22,23}$ contains the largest amount of soluble compounds among used materials. It can be assumed that extrusion process contributed to increasing the soluble substances in quince pomace more than in apple and linen pomace. Except for the solubility of material with $5 \%$ pomace addition

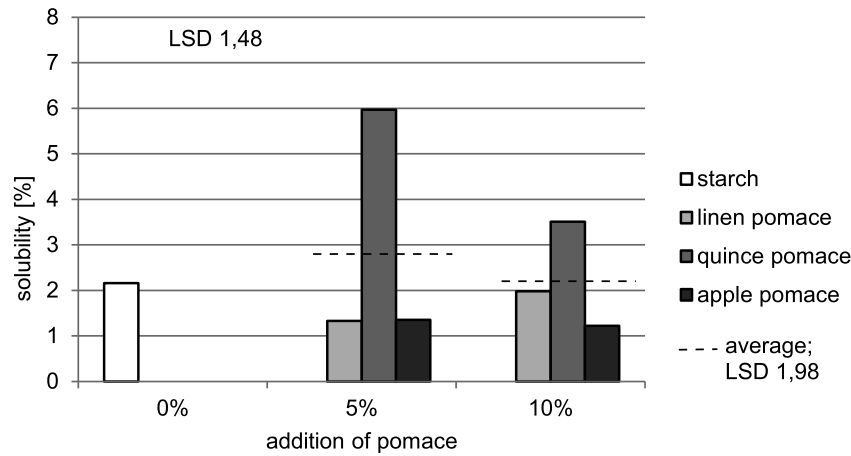

Figure 3. The solubility in water at $30^{\circ} \mathrm{C}$, depending on the size and type of pomace

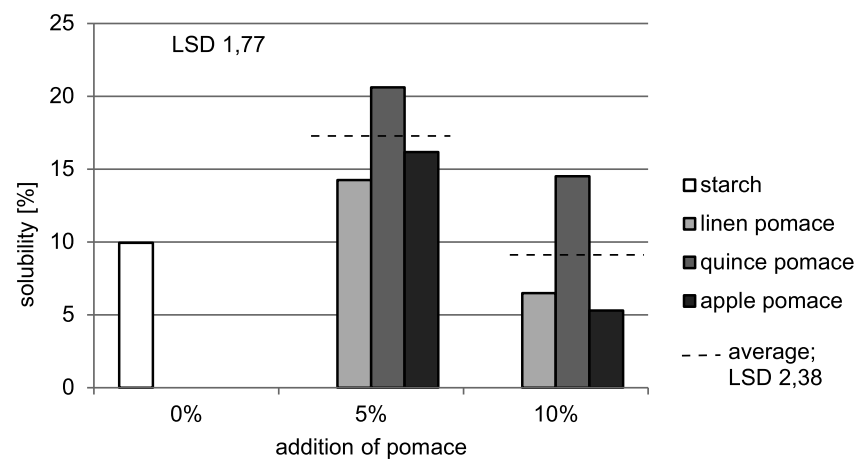

Figure 4. The solubility in water at $80^{\circ} \mathrm{C}$, depending on the size and type of pomace at $80^{\circ} \mathrm{C}$ water, apple pomace decreased the susceptibility of used material on water action.

Analyzing the influence of glycerine on the susceptibility on water action of used material it was found, that the addition of glycerine influenced both on lowering water absorption and solubility in $30^{\circ} \mathrm{C}$ water and on solubility in $80^{\circ} \mathrm{C}$ on average (Figs. 5, 6, 7, 8). This influence was increased while raising the amount of glycerine. The interesting thing is that in the glycerine-free material the addition of pomace caused the increase of mentioned values. However, while using pomace, the addition of glycerine in most cases caused decreasing of susceptibility on water action of the material containing both pomace and glycerine relative to the material with glycerine only. The biggest decreasing of susceptibility on water action

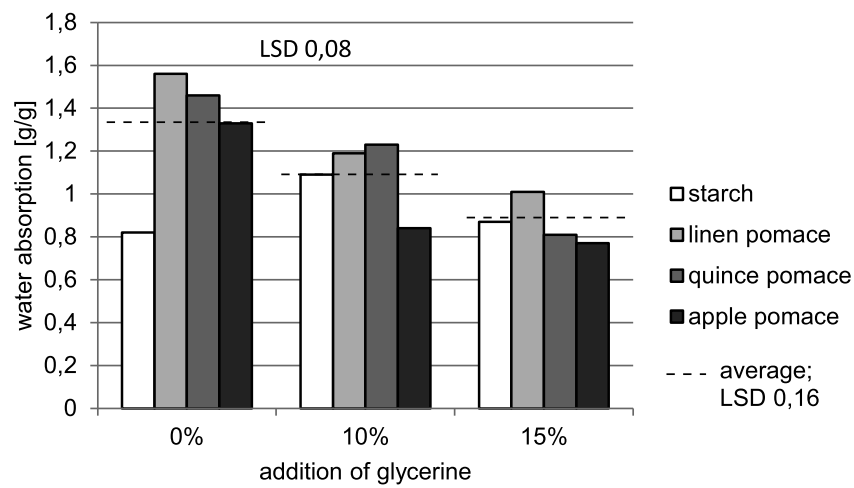

Figure 5. The water absorption at $30^{\circ} \mathrm{C}$, depending on addition of glycerine and type of pomace

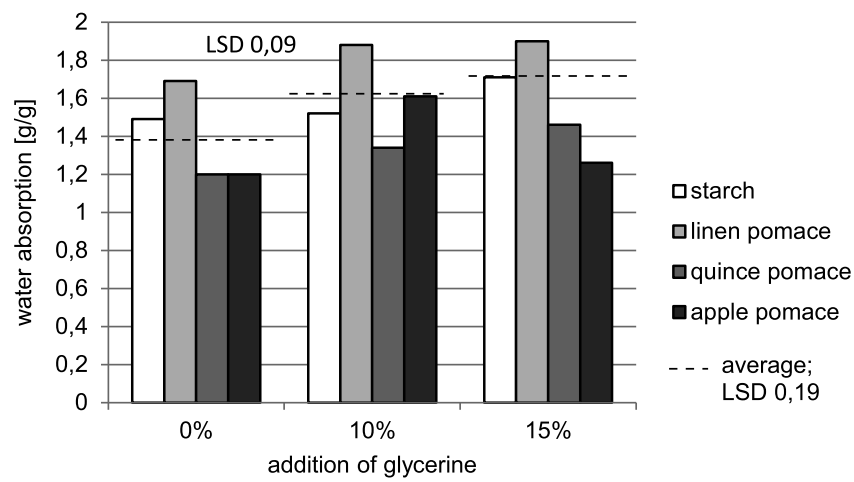

Figure 6. The water absorption at $80^{\circ} \mathrm{C}$, depending on addition of glycerine and type of pomace

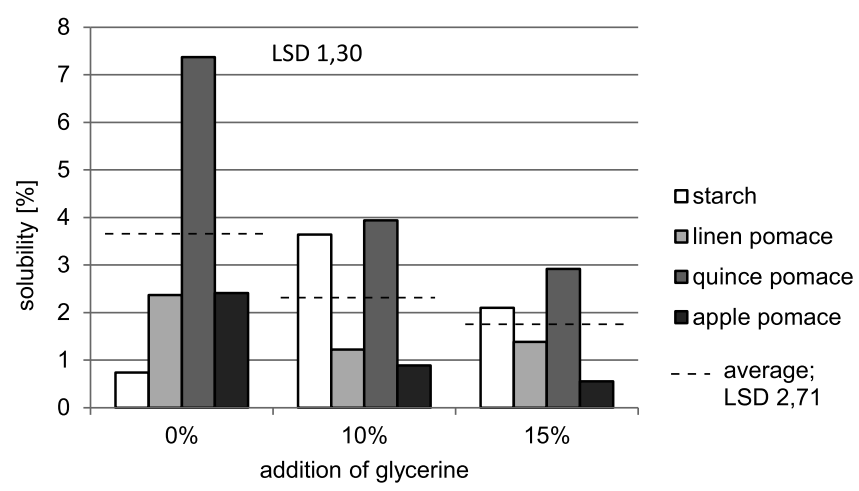

Figure 7. The solubility in water at $30^{\circ} \mathrm{C}$, depending on addition of glycerine and type of pomace

of the material produced with glycerine was received as a result of using the apple pomace.

The Figures 9 and 10 shows the time of heat penetration inside the thermal center of shape manufactured 


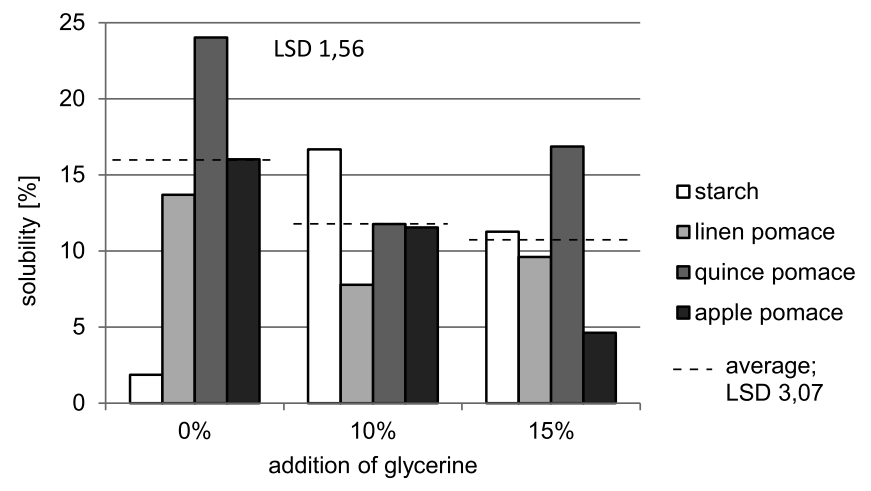

Figure 8. The solubility in water at $80^{\circ} \mathrm{C}$, depending on addition of glycerine and type of pomace

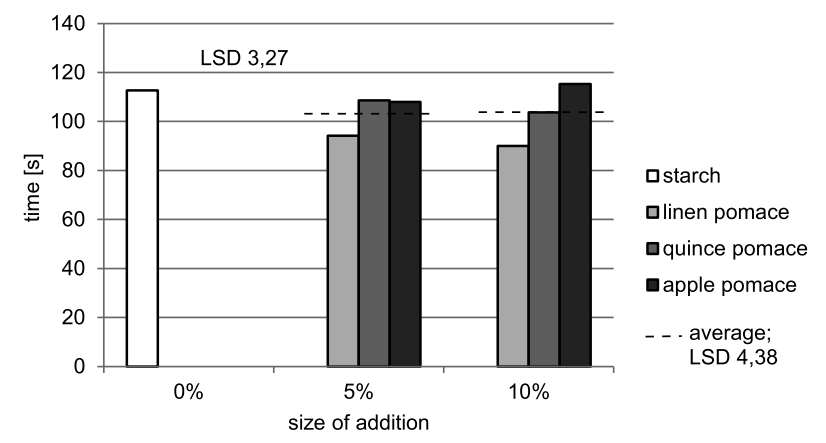

Figure 9. Heat transition time through shapes, depending on the size and type of pomace

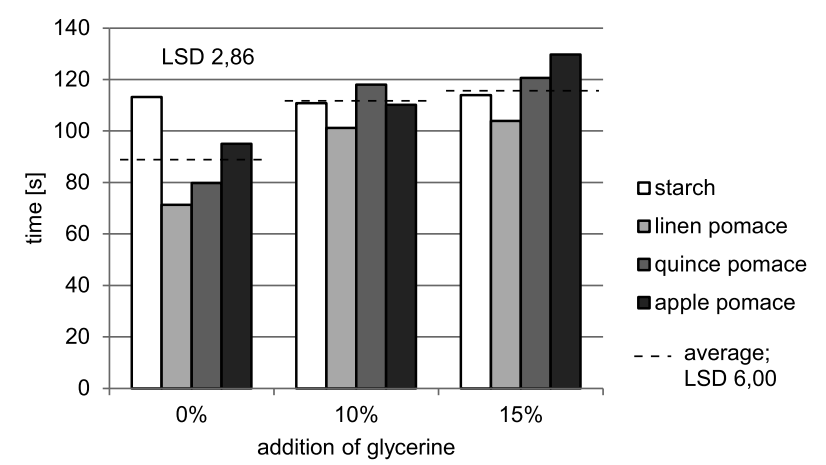

Figure 10. Heat transition time through shapes, depending on addition of glycerine and type of pomace

to form the tested material. It was stated that linen pomace decreased the thermal insulation properties. This result can be considered as confirmation of the negative influence of linen pomace on the possibilities of the material forming according to described in this experiment method. Using the apple and quince pomace didn't increase statistically the thermal conductivity of the material, whereas the apple pomace added in the amount of $10 \%$ improved the thermal insulation in comparison with other samples of the examined material. Glycerin is a commonly used plasticizer in the thermoplastic $\operatorname{starch}^{24,25,26}$. It turns out that glycerine as a plasticizer not only influences on the durability of biodegradable material made from $\operatorname{starch}^{27}$, but also raises the thermal insulation of the material. It's worth noticing that, similarly to susceptibility on water action, glycerine eliminates the negative impact of the pomace addition. This negative impact can be noticed in faster thermal insulation through the glycerine-free material (however containing pomace) in comparison with the material produced only from starch.

\section{CONCLUSIONS}

It is possible to get the biodegradable material produced from thermoplastic starch with addition of linen, quince and apple pomace

Adding pomace to the biodegradable material made from thermoplastic starch contributes to the change of susceptibility on water action. This change depends on the kind and amount of pomace addition.

Using glycerine as a plasticizer in the process of producing biodegradable materials from starch contributes to increasing the susceptibility of these materials on water action. However, in the case of materials containing pomace, glycerine addition decreases the susceptibility on water action compared to the material manufactured with pomace addition but without glycerine.

In the material containing pomace, gycerine addition caused the reduction of thermal conductivity compared to the material with pomace but no glycerine in it.

Among produced materials the most desired properties had the material with $15 \%$ of glycerine and $10 \%$ of apple pomace.

\section{ACKNOWLEDGMENT}

Publication supported by Wroclaw Centre of Biotechnology, programme The Leading National Research Centre (KNOW) for years 2014-2018.

\section{LITERATURE CITED}

1. Błędzki, A.K., Goracy, K. \& Urbaniak, M. (2012). Possibilities of recycling and utylisation of the polymeric materials and composite products (in Polish). Polimery 57, 9.

2. Rahmad, A.R., Rahman, W.A., Sin, L.T. \& Yussuf, A.A. (2009). Approaches to improve compatibility of starch filled polymer system: A review. Mater. Sci. Eng. C, 29, 237-2377. DOI: $10.1016 /$ j.msec.2009.06.009.

3. Kim, M. (2003). Evaluation of degradability of hydroxypropylated potato starch/polyethylene blend films. Carbohyd. Polym. 54, 173-181. DOI: 10.1016/S0144-8617(03)00169-3.

4. Bertuzzi, M.A., Armada, M. \& Gottifredi, J.C. (2007). Physicochemical characterization of starch based films. J. Food Eng. 82, 17-25. DOI: 10.1016/j.jfoodeng.2006.12.016.

5. Saberi, B., Thakur, R., Vuong, Q.V., Chockchaisawasdee, S., Golding, J.B., Scarlett, C.J. \& Stathopoulos, C.E. (2016). Optimization of physical and optical properties of biodegradable edible films based on pea starch and guar gum. Ind. Crip. Prod. 86, 342-352. DOI: 10.1016/j.indcrop.2016.04.015.

6. Carvalho, A.J.F., Curvelo, A.A.S. \& Agnelli, J.A.M. (2001). A first insight on composites of thermoplastic starch and kaolin. Carbohyd. Polym. 45, 189-194. DOI: 10.1016/ S0144-8617(00)00315-5.

7. Wattanakornsiri, A., Pachana, K., Kaewpirom, S., Traina. M. \& Migliaresi, C. (2012). Preparation and Properties of Green Composites Based on Tapioca Starch and Differently Recycled Paper Cellulose Fiber. J. Polym. Environ. 20, 801-809. DOI: 10.1007/s10924-012-0494-6.

8. Vasconez, M.B., Flores, S.K., Campos, C.A., Alvarado, J. \& Gerschenson, L.N. (2009). Antimicrobial activity and physical properties of chitosan-tapioca starch based edible films and coatings. Food Res. Int. 42, 762-769. DOI: 42 762-769. 10.1016/j.foodres.2009.02.026. 
9. Świerz-Motysia, B. \& Rajkiewicz, M. \& Mikołajska, A. (2007). Characterization of polimer compositions containing thermoplastic starch (in Polish). Elastomery 2(11), 10-20.

10. Jimenez, A., Fabra, M.J., Talens, P. \& Chiralt, A. (2012). Edible and Biodegradable Starch Films: A Review. Food Bioprocess. Technol. 5, 2058-2076. DOI: 10.1007/s11947-012-0835-4.

11. Gupta, A.P., Kumar, V. \& Sharma, M. (2010). Formulation and Characterization of Biodegradable Packaging Film Derived from Potato Starch \& LDPE Grafted with Maleic Anhydride-LDPE Composition. J. Polym. Environ. 18, 484-491. DOI: 10.1007/s10924-010-0213-0.

12. Nawirska, A. \& Kwaśniewska, M. (2005). Dietary fibre fractions from fruit and vegetable processing waste. Food Chem. 91(2), 221-225. DOI: 10.1016/j.foodchem.2003.10.005.

13. Nawirska, A. (2005). Binding of heavy metals to pomace fibers. Food Chem. 90(3), 395-400. DOI: 10.1016/j.foodchem.2004.04.009.

14. Zdybel, E., Tomaszewska-Ciosk, E., Główczyńska, G. \& Drożdż, W. (2014). The heat insulating properties of potato starch extruded with addition of chosen by- products of food industry. Pol. J. Chem. Technol. 16(4) 28-32. DOI: 10.2478/ pjct-2014-0065.

15. Zdybel, E. \& Leszczyński, W. (2004). The properties of plastic made from synthetic polymers and acetylated starch. (in Polish). Zesz. Probl. Postęp. Nauk Rol. 500, 569-579

16. Tomaszewska-Ciosk, E., Golachowski, A., Drożdż, W., Boruczkowski, T., Boruczkowska, H. \& Zdybel, E. (2012). Selected Properties of Single- and Double-Extruded Potato Starch. Pol. J. Food Nutr. Sci. 62(3), 171-177. DOI: 10.2478/ v10222-011-0034-4.

17. Tomaszewska-Ciosk, E., Boruczkowski, T., Golachowski, A., Drożdż, W. \& Boruczkowska, H. (2013). Effect of ethanol addition on physical properties of extruded starch. Starch/Stärke 65(3-4), 244-252. DOI: 10.1002/star.201200066.

18. Zięba, T., Kapelko, M., Gryszkin, A. \& Brzozowska, M. (2010). Physical and chemical modification of potato starch to obtain resistant starch preparations. Pol. J. Food Nutr. Sci. 60(2), 153-157.

19. Kapelko, M. \& Zięba T. (2007). Properties of extruded potato starch modified with glycin (in Polish). Żyw. Nauka. Technol. Jakość 54, 21-30.

20. Kita, A. \& Popiela-Kukuś, K. (2010). Effect of flaxseed pomace addition on selected properties of fried potato snacks (in Polish). Acta Agrophys. 16(1), 69-77.

21. Figuerola, F., Hurtado, M.L., Estevez, A.M., Chiffelle I. \& Asenjo, F. (2005). Fibre concentrates from apple pomace and citrus peel aspotential fibre sources for food enrichment. Food Chem. 91, 395-401. DOI: 10.1016/j.foodchem.2004.04.036.

22. Sudha, M.L., Baskaran, V. \& Leelavathi K. (2007) Apple pomace as a source of dietary fiber and polyphenols and its effect on the reological characteristics and cake making. Food Chem. 104, 686-692. DOI: 10.1016/j.foodchem.2006.12.016.

23. Zhang, Y. \& Thompson, M. \& Liu, Q. (2011). The effect of pea fiber and potato pulp on thermal property, surface tension, and hydrophilicity of extruded starch thermoplastics. Carbohyd. Polym. 86, 700-707. DOI: 10.1016/j.carbpol.2011.05.009.

24. Jiménez, A., Fabra, M.J., Talens, P. \& Chiralt, A. (2012). Edible and Biodegradable Starch Films: A Review. Food Bioprocess. Technol. 5, 2058-2076. DOI: 10.1007/s11947-012-0835-4.

25. Lu, D.R., Xiao, C.M. \& Xu S.J. (2009). Starch-based completely biodegradable polymers materials. Express Polym. Lett. 3, 6, 366-375. DOI: 10.3144/expresspolymlett.2009.46.

26. Cyras, V.P., Manfredi, L.B., Ton-That, M.T. \& Vázquez, A. (2008). Physical and mechanical properties of thermoplastic starch/montmorillonite nanocomposite films. Carbohyd. Polym. 73, 55-63. DOI: 10.1016/j.carbpol.2007.11.014.

27. Mali, S., Sakanaka, L.S., Yamashita, F. \& Grossmann, M.V.E. (2005). Water sorption and mechanical properties of cassava starch films and their relation to plasticizing effect. Carbohyd. Polym. 60, 283-289. DOI: 10.1016/j.carbpol.2005.01.003. 